patients with EC and healthy female subjects. MiRNA was isolated and qPCR was used to detect expression levels of miRNAs.

Results A total of 76 women were included; 36 EC patients, 40 healthy controls. A distinct panel of miR-200a, miR-200b, miR-200c, miR-205 and miR-182 showed AUC of 0.958, sensitivity $92 \%$, specificity $89 \%$, positive predictive value of $89 \%$ and negative predictive value of $91 \%$ in diagnosing EC. MiR182 expression levels were significantly related to high-grade endometrioid tumours compared to low grade.

Conclusion We demonstrated high diagnostic accuracy of miRNA for detecting EC. In addition, miRNA contributed to improved distinguishing between high-grade and low-grade endometrioid tumours. Validation of miRNA expression levels in urine will be performed in order to further optimise a non-invasive diagnostic tool.

\section{IGCS20 1465}

\section{PROSPECTIVE EVALUATION OF AN ERAS PATHWAY AT A GYNAECOLOGICAL ONCOLOGY UNIT IN OSLO, NORWAY}

${ }^{1,2} \mathrm{~K}$ Lindemann* ${ }^{3}{ }^{3} \mathrm{~B}$ Eyjólfsdóttir, ${ }^{4} \mathrm{~S}$ Heimisdottir Danbolt, ${ }^{1} \mathrm{Y} Y$ Wang, ${ }^{5} \mathrm{~A}$ G Heli-Haugestøl, ${ }^{5} \mathrm{H}$ Thorsrud, ${ }^{2} \mathrm{TK}$ Nguyen, ${ }^{6} \mathrm{O}$ Mjåland, ${ }^{1} \mathrm{GA}$ Navestad, ${ }^{1} \mathrm{~S}$ Hermanrud, ${ }^{7} \mathrm{~K}$ E Juul-Hansen, ${ }^{8,9} \mathrm{~A}$ Kleppe, ${ }^{1} \mathrm{~T}$ Skeie-Jensen, ${ }^{2,7} \mathrm{U}$ Kongsgaard. ${ }^{1}$ Department of gynecologic oncology, Oslo University Hospital; ${ }^{2}$ Institute of clinical medicine, University of Oslo: ${ }^{3}$ Department of gynecologic oncology, Oslo University Hospital; ${ }^{4}$ Institute of health and society, University of Oslo; ${ }^{5}$ Department of Clinical Service, Oslo University Hospital; ${ }^{6}$ Department of gastroenterological surgery, Oslo University Hospital; ${ }^{7}$ Department of anesthesiology, Oslo University Hospital; ${ }^{8}$ Institute for Cancer Genetics and Informatics, Oslo University Hospital; ${ }^{9}$ Department of Informatics, University of Oslo, Oslo, Norway

\subsection{6/ijgc-2020-IGCS.371}

Introduction We prospectively evaluated an ERAS in a large gynaecologic oncology tertiary centre serving the South East Health region in Norway.

Methods Patients undergoing laparotomy for (suspected) ovarian cancer at the Oslo University Hospital were prospectively included in a pre-implementation and post-implementation cohort. Baseline characteristics, adherence to the pathway and clinical outcomes were assessed.

Results Of the 439 patients, 235 (54\%) underwent surgery for advanced ovarian cancer and 204 (46\%) for a suspicious ovarian mass. Median fasting times for solids (13 vs $16 \mathrm{~h}$, $\mathrm{p}<0.001)$ and fluids $(3.7$ vs $11.9 \mathrm{~h}, \mathrm{p}<0.001)$ were significantly reduced. Perioperative fluid administration varied less $(\mathrm{p}<0.001)$ and was reduced (median 11.5 vs $15.8 \mathrm{ml} / \mathrm{kg} / \mathrm{h}$, $\mathrm{p}<0.001$ ). Epidural analgesia was the mainstay of analgesia in both cohorts, but with ERAS more patients received continuous vasopressor intraoperatively $(87 \%$ vs $70 \%, p=0.003)$. More patients received dual PONV prophylaxis $(85 \%$ vs $64 \%, p<0.001)$. Length of stay remained unchanged for patients with advanced disease with a median of 5 days both before and after the implementation $(p=0.94)$, but patients undergoing surgery for an ovarian mass stayed shorter in hospital after the implementation of ERAS $(p=0.026)$. For all patients, more patients were discharged directly home as opposed to transferred to local referring hospital after ERAS implementation $(70 \%$ vs $51 \%, \mathrm{p}<0.001)$. There was no difference in re-admission rates or postoperative $30 \mathrm{~d}$ morbidity.
Conclusion Introduction of an ERAS pathway resulted in less variance in practice and increased adherence to current standards in perioperative management. Patients were more often able to be discharged directly home without an increase in admission rates.

\section{IGCS20_1466}

\section{IDENTIFICATION OF CLINICOPATHOLOGICAL PROGNOSTIC FACTORS IN RECURRENT ENDOMETRIAL CANCER}

Y Koike*, M Takenaka, J Suzuki, Y Shoburu, K Tomita, A Ikenaga, M Kamii, S Hirose, H Takano, K Yamada, S Niimi, A Okamoto. The Jikei University School of Medicine, Japan

\subsection{6/ijgc-2020-IGCS.372}

Objectives Although, endometrial cancer (EC) is commonly diagnosed at an early stage and has a favorable prognosis, recurrent disease usually shows poor prognosis. However, clinicopathological prognostic factors for recurrent EC have been still unclear. The current study aimed to identify clinicopathological prognostic factors, especially in long term survivors of recurrent EC.

Methods We collected 2044 patients who underwent surgery including hysterectomy and were pathologically diagnosed as EC in our hospitals between 2001 and 2018. Clinicopathological information and survival data were retrospectively obtained by the review of medical record. Among 2044, 131 patients were included in this retrospective analysis. In recurrent cases, we analyzed the prognostic factors for long-term survivors of recurrent EC. Then we defined long-term and short-term survivors, as patients who survived $\geqq 3$ years (n $=53)$ and died within 3 years $(n=78)$ after first recurrence, respectively. The correlation between prognosis and clinicopathological factors was statistically analyzed.

Results In the multivariate analysis of long-term survivors, we identified that TTP $\geqq 1$ year after surgery $(\mathrm{P}<0.01)$, surgical reduction of the first recurrence $(\mathrm{P}=0.03)$, non-peritoneal metastasis $(\mathrm{P}=0.045)$, were significantly associated with the long-term survivors of recurrent EC.

Conclusion TTP $\geqq 1$ year after surgery, non-peritoneal metastasis, surgical reduction of first recurrence were good prognostic factors of long-term survivors in recurrent EC.

\section{IGCS20_1467}

\section{MACHINE LEARNING MODELS TO PREDICT SURVIVAL OUTCOMES AFTER RADICAL HYSTERECTOMY ACCORDING TO SURGICAL APPROACH IN PATIENTS WITH FIGO STAGE IB CERVICAL CANCER}

${ }^{1} \mathrm{~S}$ Kim*, ${ }^{*} \mathrm{C}$ Choi, ${ }^{1} \mathrm{M}$ Lee, ${ }^{3} \mathrm{DH}$ Suh, ${ }^{1} \mathrm{~J} \mathrm{Kim},{ }^{3}{ }^{\mathrm{Y} B} \mathrm{Kim} .{ }^{1}$ Seoul National University College of Medicine, South Korea; ${ }^{2}$ Samsung Medical Center, South Korea; ${ }^{3}$ Seoul National University Bundang Hospital, South Korea

\subsection{6/ijgc-2020-IGCS.373}

Objective To develop preoperative machine learning models predicting survival outcomes according to the surgical approach in early-stage cervical cancer. 